\title{
O PAPEL MOTIVADOR DOS ROMANCES DE CAVALARIA EM TORNO DAS VIAGENS À AMÉRICA ESPANHOLA NO PERÍODO DA CONQUISTA
}

\author{
Tamara de Lima
}

Instituto Federal de Educação, Ciência e Tecnologia de São Paulo - IFSP; Coordenadoria Sociopedagógica, Presidente Epitácio, SP. E-mail: tamara.lima@ifsp.edu.br. Agência de fomento: Fundação de Amparo a Pesquisa do Estado de São Paulo - FAPESP.

\section{RESUMO}

As viagens rumo ao Novo Mundo despertaram o interesse de centenas de europeus na época moderna. As possibilidades que essa nova terra oferecia aos espanhóis, os motivos que os animavam a se aventurarem em expedições conquistadoras é algo que buscamos compreender neste artigo. Nosso estudo teve como objetivo analisar o papel motivador que os chamados romances de cavalaria exerceram acerca do imaginário em torno de terras desconhecidas ligado à esperança de obtenção de riquezas, honra e fama. A metodologia constou da análise de alguns desses romances do período cotejados com a literatura específica. Os resultados apontam que esse imaginário em grande medida era alimentado por esses textos, o que nos leva a concluir que eles acabavam por exercer papel motivador para essas viagens, além de propagarem um ideal cavaleiresco a ser conquistado nas terras de além-mar.

Palavras-chave: América espanhola, imaginário, século XVI, viagens, romances de cavalaria.

\section{THE MOTIVATING ROLE OF CAVALRY NOVELS AROUND THE TRAVELS TO SPANISH AMERICA AT THE PERIOD OF CONQUEST}

\begin{abstract}
Travel to the New World has attracted the interest of hundreds of Europeans in modern times. The possibilities that this new land offered the Spaniards, the motives that encouraged them to venture into conquering expeditions is something we seek to understand in this article. Our study aimed to analyze the motivating role that the so - called cavalry novels have played in the imaginary around unknown lands linked to the hope of obtaining riches, honor and fame. The methodology consisted of the analysis of some of these romances of the period compared with the specific literature. The results indicate that this imaginary was largely fed by these texts, which leads us to conclude that they ended up playing a motivating role for these journeys, as well as propagating a chivalrous ideal to be conquered in the overseas lands.
\end{abstract}

KEYWORDS: Spanish America, imaginary, sixteenth century, travels, cavalry novels. 


\section{INTRODUÇÃO}

O gosto do desconhecido e do mistério não podia deixar de atrair para fora da Europa os temperamentos aventureiros. Todo um conjunto de mitos e fábulas reforçou nos mais audazes ocidentais o duplo desejo de enriquecer e alargar o domínio da igreja de Cristo. (DELUMEAU, 1984, p. 50)

Embarcar para as Índias rumo ao desconhecido foi algo que atraiu centenas de aventureiros durante o período de "descoberta" e conquista da América. De antemão, seguindo a citação acima, podemos elencar o desejo de enriquecimento rápido e o ideal de expansão da fé católica, a que devemos acrescentar a busca por honra e fama. Ainda, de acordo com o que nos diz Jean Delumeau acerca de "um conjunto de mitos e fábulas", não devemos nos esquecer de que esses ideais que envolviam a "aventura das Índias" eram alimentados por um imaginário fascinante em torno das terras de além-mar.

Os mitos sempre estiveram presentes no imaginário dos homens e sempre atuaram sobre seu comportamento, mas na época das descobertas tiveram um papel verdadeiramente mobilizador e determinaram as ações de muitos indivíduos que vieram tentar a sorte no Novo Mundo (MAGASICH-AIROLA; DE BEER, 2000, p. 17). Muitas expedições foram organizadas em busca de regiões míticas e de fortunas incalculáveis. Muitas também foram as vidas que se perderam na tentativa de encontrar o Paraíso, a fonte da juventude, o El Dorado, as minas do rei Salomão, as amazonas e toda uma série de seres prodigiosos, para citar alguns dos elementos míticos que povoavam a imaginação dos conquistadores - reavivada com a chegada de Cristóvão Colombo ao Novo Mundo e as notícias registradas em seus Diários.

Esse imaginário fora estimulado em grande medida pela literatura cavaleiresca, tão em voga nesse momento. As expectativas que o Novo Mundo oferecia ao horizonte desses homens, os motivos que os animava a se aventurarem nessas expedições conquistadoras é algo que objetivamos compreender.

\section{METODOLOGIA}

Essa pesquisa é de natureza qualitativa, de abordagem descritivo-analítica. Para a consecução dos objetivos propostos utilizamo-nos da análise dos romances de cavalaria do século XVI cotejados com literatura específica. Essa análise teve como foco mapear possíveis elementos que poderiam ter exercido um papel motivador para as viagens rumo à América no século XVI.

Sobre os romances de cavalaria, podemos afirmar que o gosto por esse gênero literário era bem difundido na Espanha, possuía admiradores desde os mais cultos, como o próprio imperador Carlos V, até seus mais humildes servidores. Essas histórias, muitas vezes, eram lidas em voz alta para que os iletrados pudessem apreciá-las. Na verdade, antes de 1500, muitas dessas narrativas chegavam aos ouvidos dos espanhóis através da oralidade, por meio daqueles que contavam contos ou pelos romances cavaleirescos dos trovadores e passavam de boca em boca. A Espanha desse período, ainda era uma sociedade essencialmente de ordem oral (VIÑAO FRAGO, 1999, p. 73), não uma "oralidade primária", sem contato algum com a escrita, mas uma "oralidade segunda", baseada no uso de escritos, em que estes tendiam a suplantar o valor da voz no uso e no imaginário (ZUMTHOR, 1993, p. 18)

Com a recém-inventada máquina de imprensa, a credulidade dos ouvintes podia também ser estimulada pela evidência visual da obra impressa, ou seja, o que eles já haviam escutado, agora era confirmado pela palavra escrita. A partir daí, esses contos podiam também acompanhar os conquistadores em suas travessias do Atlântico (LEONARD, 1996). 


\section{RESULTADOS}

Cronologicamente, a primeira obra representativa do gênero que surgiu na Espanha foi Historia del caballero de Dios que avia por nombre Cifar, mas, pelo que consta, essa obra só apareceu impressa por volta de 1512 e não foi muito conhecida. Tirant lo Blanch (Tirante, o branco), provavelmente foi o primeiro a ser impresso em solo espanhol, em língua catalã, em 1490. Em 1511 surgiu sua versão em castelhano com êxito relativamente moderado.

O romance mais popular entre eles era o Amadís de Gaula, impresso pela primeira vez em 1508. França, Portugal e Espanha reclamam para si a origem da obra que é referenciada desde o século XIV na Península Ibérica. O título dessa primeira versão impressa é Cuatro libros de Amadís de Gaula cujo autor seria Garci-Rodríguez de Montalvo que, em edições posteriores aparece como Garci-Ordóñez de Montalvo, que teria escrito o prólogo de seu livro entre 1492 e 1504, único dado que se conhece a seu respeito, além do fato de que trabalhava em Medina Del Campo. A distância cronológica com que a obra já é referenciada - século XIV - e a data em que o nome de Montalvo aparece na primeira versão impressa como seu autor, pareceu-nos significativo da falta de sentido que esta noção, a de autoria, tem para a época (FOUCAULT, 1992, p. 47).

$O$ romance, resumidamente, narra a origem e as aventuras de Amadís e seu amor por Oriana, filha de Lisuarte, rei da Bretanha. A história não foge às constantes do gênero: Amadís é filho de nobres, mas não conhece sua origem, se apaixona por uma princesa e se entrega à cavalaria para conseguir, através de seu esforço, a mão de sua amada. As aventuras de Amadís estão repletas de combates individuais e coletivos, resgates de donzelas, monstros e ilhas encantadas. Por fim, por suas notáveis proezas é recompensado com a glória e se casa com sua amada.

Durante todo o século XVI, Amadís foi a obra favorita de inumeráveis leitores, um manual e modelo de bom gosto, valor e nobreza. Mas, sobretudo, o panorama de ilhas exóticas, seres estranhos e tesouros escondidos contidos em suas páginas estimularam seus leitores a lançaremse em aventuras através do mundo (LEONARD, 1996, p. 29).

Em 1510, apareceu assinado pelo mesmo Montalvo, Las Sergas de Esplandián que narra as aventuras do filho de Amadís. Essa obra obteve relativo êxito, alcançou mais ou menos umas dez edições ao longo do século XVI e inclui em sua narrativa o mito Antigo das amazonas, o que provavelmente movimentou a imaginação dos conquistadores espanhóis - basta lembrarmos a quantidade de relatos sobre o Novo Mundo em que essas mulheres guerreiras são mencionadas. $A$ essa obra, seguiram-se várias outras: entre 1508 e 1550 foram publicados mais de 50 livros de cavalaria. Os filhos, netos e bisnetos de Amadís e Esplandián perpetuaram as tradições da família ao longo desse século nas páginas de Florisando, publicado no mesmo ano que Las Sergas de Esplandián, Lisuarte de Grécia (1514), Amadís de Grécia (1530), Don Florisel de Niquea (1532) e vários outros, até que o "ciclo de Amadís" compôs-se por doze livros (LEONARD, 1996, p. 30).

A popularidade dessas novelas no século XVI foi, na realidade, um reviver da paixão medieval pela literatura cavaleiresca: continha alguns dos mesmos elementos fantásticos e idealizantes mesclados com certos aspectos históricos (LEONARD, 1996, p. 30), pois existiam algumas constantes nessa literatura que emprestavam um ar de veracidade à narrativa. Estes romances eram baseados em um suposto manuscrito antigo descoberto e traduzido pelo autor, o que dava a impressão de que a narrativa provinha de um documento histórico.

Assim, a historicidade aparente desses relatos aliada ao alargamento do horizonte geográfico advindo das recentes descobertas da África e do Novo Mundo, tornavam verossímeis as fantasias com as quais os escritores enriqueciam suas obras. As enormes possibilidades que 0 globo terrestre parecia oferecer reavivavam a imaginação dos leitores, levavam os mais aventureiros a procurar as maravilhas e os tesouros ocultos, cuja existência era afirmada com tanta autoridade. Outras invariáveis nesses romances dizem respeito ao herói, de origem nobre, porém obscura, que através de seu esforço pessoal - medido por sua coragem e façanhas 
extraordinárias - conquistava fama e riqueza e era recompensado com a obtenção de um reino exótico ou uma ilha encantada. Além disso, essas histórias se passavam em ambientes difíceis de localizar, com cidades exuberantes ou lugares mágicos (LEONARD, 1996, p. 31).

\section{DISCUSSÃO}

A influência que a literatura cavaleiresca exercia nos conquistadores pode ser verificada mais de forma indireta, ou seja, ligada aos hábitos, à conduta, à moral e ao imaginário, pois não abundam nos relatos sobre a conquista do Novo Mundo, menções diretas a esse gênero literário. Irving Leonard (1996, p. 68-69) esboçou algumas reflexões em torno dessa escassez que devem ser mencionadas. Primeiramente, muitos desses homens eram quase ou totalmente analfabetos e não puderam escrever suas aventuras e nem, portanto, deixar alguma prova escrita de sua afeição pelos romances cavaleirescos que conheciam, provavelmente, por terem ouvido sua leitura ou presenciado alguma discussão sobre o tema. Mesmo entre os letrados, poucos foram os que deixaram suas impressões escritas e a maioria não parou para refletir em seus textos sobre influências subjetivas, dando mais atenção aos aspectos externos de suas aventuras. Assim, é difícil encontrar grandes considerações a respeito dessa literatura, presença perceptível, contudo, nas descrições que oferecem os cronistas ao relatarem suas impressões sobre a nova terra e povos que tinham diante dos olhos.

A essa causa, acrescenta-se a hostilidade das autoridades eclesiásticas e seculares contra essa literatura, pois acreditavam que a mesma interferia na conduta e na moral das jovens senhoritas - afeitas a essas leituras -, bem como da juventude masculina que as preferiam em detrimento do estudo de obras hagiográficas e devocionárias. Esses clérigos se preocupavam, sobretudo, com o efeito inebriante que tais romances provocavam: descrições de ouro, prata, pedras preciosas, terras exóticas e seres fantásticos, leitura com certeza bem mais instigante que a religiosa (LEONARD, 1996, p. 70).

Os reis católicos não deixaram de perceber o êxito que os romances de cavalaria alcançaram, um tipo de literatura que consideraram imprópria para os jovens e para algumas de suas empresas políticas, e a proibiram. Mas, na Espanha, apesar da condenação da Igreja, de moralistas e da coroa, tais obras não foram alvos de uma perseguição ativa, ao contrário do que ocorrera nas Índias; acreditavam que os indígenas poderiam "confundir" o conteúdo das Sagradas Escrituras com os "costumes errôneos" veiculados por essas histórias, o que dificultaria o processo de evangelização. Assim, por cédula real de 4 de abril de 1531, o rei Carlos $V$ ordenou que se evitasse o envio ao Novo Mundo de "romances de histórias vãs e profanas como o Amadís", proibição reiterada em 1534. Contudo, apesar dos impedimentos, livreiros, impressores e comerciantes continuaram seu próspero negócio de exportar as histórias sobre as vidas e feitos dos cavaleiros imaginários para as Índias (GONZÁLEZ SÁNCHEZ, 2003, p. 85).

Sobre as maravilhas que povoavam o imaginário desses homens, vale destacar o estudo de Guillermo Giucci (1992), para quem, na América, o maravilhoso e a imagem das riquezas coincidiram, ou seja, a ideia de maravilhoso estava ligada à esperança de enriquecimento rápido. Mas, depois que a vivência se sobrepôs à imaginação, esse maravilhoso foi-se fragmentando e em fins do século XVI já não desempenhava um papel tão importante como antes, em que havia sido o grande elemento propulsor da conquista da América espanhola. Assim, para ele, o maravilhoso americano estava menos povoado por realidades fantásticas do que pela expectativa de encontrar metais preciosos em abundância.

Devemos assinalar que a ânsia pela descoberta de riquezas minerais também era precedida por lendas que ressurgiram nesse momento como as minas do rei Salomão e a Aurea Chersonesus - a "península do Ouro" que o geógrafo Cláudio Ptolomeu situara nos confins do Oriente (MAGASICH-AIROLA; DE BEER, 2000, p. 98) - que, a nosso ver, também faziam parte do maravilhoso americano. Mais ou menos por volta de 1511, os espanhóis ouvem falar pela primeira 
vez sobre as riquezas do Tawantinsuyu ${ }^{1}$; no Panamá, um cacique revelou a Vasco Nuñez de Balboa sobre a existência de uma terra situada mais ao Sul onde encontraria ouro em abundância. Como rumores desse tipo não podiam deixar indiferentes os habitantes da Península Ibérica, expedições foram organizadas à procura desse território fabuloso.

Francisco Pizarro fora um desses homens atraído por tais rumores, fracassara nas duas primeiras tentativas, mas em 1532 quando captura o soberano Atahualpa e toma posse do Tawantinsuyu, as lendas pareciam ter se tornado realidade - assim como acontecera na conquista de Tenochtitlán por Cortez -, pois as riquezas minerais encontradas pareciam inesgotáveis. Os navios atravessavam o oceano abarrotados por ouro e prata que, sob a forma de lingotes, vasos, pedrarias e estátuas foram desembarcados nos portos ibéricos, para a contemplação de seus habitantes. As notícias sobre a existência de reinos tão ricos e fabulosos conquistados por Cortez e Pizarro só fez aguçar a esperança de outros aventureiros; boatos sobre outros reinos tão ou mais ricos do que os encontrados surgiram e várias expedições foram organizadas com o intuito de encontrá-los e repetir as proezas dos dois capitães (MAGASICH-AIROLA; DE BEER, 2000, p. 109).

\section{CONCLUSÃO}

Acerca do alcance da literatura cavaleiresca na vida dos homens desse período, podemos mencionar o fato de que esses romances ofereciam um código de conduta do cavaleiro, a saber, a busca por honra e fama e também de riquezas e reinos (VALCÁRCEL MARTíNEZ, 1997, p. 292)). Esses livros apresentavam um modelo de homem virtuoso a ser imitado pela sociedade renascentista: aceitação estoica de desventuras e obstáculos, exaltado sentido de honra e dignidade pessoal, hábitos corteses e um conceito cavalheiresco de amor. Tudo isso refletia os ideais da moral do homem espanhol (LEONARD, 1996, p. 43). Recordemos também que esta é uma sociedade que acaba de finalizar a Reconquista e, consequentemente, valores como a valentia guerreira, a audácia, a lealdade, em suma, o "ideal cavaleiresco" se faziam muito presentes.

Em relação aos conquistadores do Tawantinsuyu, podemos afirmar que para Francisco Pizarro, como para a grande maioria dos homens que o acompanhavam, não oriundos de linhagens nobres, a "aventura das Índias" significava o sonho de um futuro melhor, haja vista que não podiam esperar muito da sociedade à qual pertenciam. Sendo assim, não tinham tanto o que perder ao tentar conquistar, através da espada, a posição e o prestígio que lhes era recusado no Velho Mundo. A maioria dos espanhóis que se arriscaram rumo às Índias era composta de jovens e solteiros, provenientes das camadas baixas da sociedade (LOCKHART, 1986, p. 39-45).

Enobrecer com a aquisição de títulos ou pelo menos viver com nobreza era um estímulo muito poderoso para esses homens, cuja sede por riquezas era incentivada pelo poder que outorgava, pela honra que permitia. A obtenção de riquezas também estava ligada ao "pagamento" que esses homens recebiam por terem prestado serviços à Coroa de Espanha alargando o seu Império e consequentemente o da cristandade, de modo que o ideal de expansão da fé católica não era incompatível com a busca por fortuna, ou seja, os conquistadores se viam em pleno direito de receber recompensas econômicas da Coroa por desempenharem um trabalho em nome da santa fé católica. $O$ ideal de expansão do cristianismo era um estimulador e também servia para justificar a conquista.

\footnotetext{
${ }^{1}$ As quatro partes que formavam o território dos Incas: Antesuyu, Colassuyu, Contisuyu e Chinchasuyu. In: GONZALEZ HOLGUIN, Diego. Vocabulario de la lengua general de todo el Perú llamada qquichua o del Inca. Lima: UNMSM, 1989, p. 336. 


\section{REFERÊNCIAS}

DELUMEAU, Jean. A civilização do Renascimento. Lisboa: Estampa, 1984.

FOUCAULT, Michel. O que é um autor? Lisboa: Vega, 1992.

GONZALEZ HOLGUIN, Diego. Vocabulario de la lengua general de todo el Perú llamada qquichua o del Inca. Lima: UNMSM, 1989.

GONZÁLEZ SÁNCHEZ, Carlos Alberto. Cerco a la imaginación: lectura y censura ideológica en la España del siglo XVI. In: CASTILLO GÓMEZ, Antonio (Ed.). Libro y lectura en la Península Ibérica y América (siglo XIII al XVIII). Salamanca: Junta de Castilla y León, 2003.

GIUCCI, Guillermo. Viajantes do maravilhoso: o Novo Mundo. São Paulo: Companhia das Letras, 1992.

LEONARD, Irving A. Los libros del conquistador. México, FCE, 1996.

LOCKHART, James. Los de Cajamarca: un estudio social y biográfico de los primeiros conquistadores del Perú. Lima: Editorial Milla Batres, 1986, v. 1.

MAGASICH-AIROLA, Jorge; DE BEER, Jean-Marc. América Mágica: quando a Europa da Renascença pensou estar conquistando o Paraíso. São Paulo: Paz e Terra, 2000.

VALCÁRCEL MARTÍNEZ, Simón. Las crónicas de Indias como expresión y configuración de la mentalidad renacentista. Granada: Diputación Provincial, 1997.

VIÑAO FRAGO, Antonio. Alfabetización y primeras letras (siglos XVI y XVII). In: CASTILLO GÓMEZ, Antonio (Org.). Escribir y leer en el siglo de Cervantes. Madrid: Gedisa, 1999.

ZUMTHOR, Paul. A letra e a voz. A “literatura” medieval. São Paulo: Companhia das Letras, 1993. 